\title{
FRACTIONAL CALCULUS: AN APPROACH TO THE ATMOSPHERIC DISPERSION EQUATION USING CONFORMABLE DERIVATIVE
}

\author{
José Roberto Dantas da Silva a, Paulo Henrique Farias Xavier a, Anderson da Silva \\ Palmeira ${ }^{a}$, Davidson Martins Moreira ${ }^{a}$. \\ a Centro Universitário SENAI CIMATEC, Salvador, Bahia, Brasil.
}

\begin{abstract}
This work presents a brief historical introduction to fractional calculus, which appeared at the end of the $17^{\text {th }}$ century, followed by a recent formulation showing the state of art, using the conformable derivative. In this context, a solution to the problem of pollutant dispersion in the atmospheric boundary layer is obtained using the Laplace decomposition method (LDM), also seeking an alternative to the problem of dimensional incompatibility that arises from this type of approach.
\end{abstract}

Keywords: Fractional calculus; Conformable derivative; Laplace decomposition method; Pollutant dispersion.

\section{CÁLCULO FRACIONÁRIO: UMA ABORDAGEM PARA A EQUAÇÃO DE DISPERSÃO ATMOSFÉRICA USANDO DERIVADA CONFORMÁVEL}

Resumo: Este trabalho apresenta uma breve introdução histórica ao cálculo fracionário, surgido no final do século XVII, seguida de uma formulação recente mostrando o estado da arte, através da utilização da derivada conformável. Neste contexto, obtém-se uma solução para o problema de dispersão de poluentes na camada limite atmosférica usando o método da decomposição por Laplace (LDM), buscando também uma alternativa para o problema de incompatibilidade dimensional que surge neste tipo de abordagem.

Palavras-chave: Cálculo fracionário; Derivada conformável; Método da decomposição por Laplace; Dispersão de poluentes. 


\section{INTRODUCTION}

The literature shows a classic definition of the theory of calculus (integer order calculus) starting with the works of Newton (Newtonian calculus) and Leibniz (Leibnizian calculus), following the different principles and solution techniques, applied for over 300 years. The conversations started with the famous correspondences between L'Hôpital and Leibniz still produce discussions about derivatives of noninteger order, called fractional calculation (FC) [1,2].

Thus, the new calculation (fractional calculus) remains inserted in the world of natural phenomena, from the reflections on the potential of the applications of the calculus of integer order, and also with the contributions of several historical personages in this field of science. Both, integer calculus and fractional calculus, equally and in a complementary way, make up the general theory of calculus and aim to study phenomena that involve movement and variation associated with the concepts of derivatives and integrals.

Still, in the 17th century, Leibniz algebraizes the concepts of variables, constants, and parameters, denoting $d y / d x$ as "differentials" that represent "the smallest possible differences in $y$ and $x$ ", introducing the concept of infinitesimal or differential calculus. Other pioneering researchers stood out for their historical relevance, such as the first book on fractional calculus entitled "Analysis of Infiniment Petits Pour l'intelligence des lignes courbes", published in 1696, by Guillaume François Antoine L'Hospital, better known as Marquis L'Hôpital [3,4]

The first application of the FC by Niels Henrik Abel, a Norwegian mathematician, in 1823, was to solve an integral equation of the called tautochrone or isochronous problem. The first monograph on fractional calculus, published in 1968, with a focus on application in chemistry, was jointly prepared by Keith B. Oldham (chemist) and Jerome Spanier (mathematician), addressing problems of mass and heat transfer in terms of semi-derivatives and semi-integral. Also, in June 1974 the "First Conference on Fractional Calculus and its Applications" was held at the University of New Haven, organized by Bertham Ross. Since then, many discussions and papers have been published on this important and challenging topic $[4,5]$.

In this sense, the present work proposes a solution of the fractional twodimensional diffusion-advection equation, using the methodology called "conformable derivative" [6], together with the Laplace decomposition method (LDM). The essential idea of this method is a change of variable, leading to a simple solution, the result of this combination is an elegant procedure that provides a closed solution, obtained through a series that converges quickly.

\section{METHODOLOGY}

The LDM method is a good tool to solve the advection-diffusion equation in atmospheric problems. In this sense, the literature focusing on the development and improvement of this methodology is very extensive [7,8,9, and 10].

However, the conformable derivative presents a new and easy definition for fractional derivatives, but it has not yet been used in the literature in problems of dispersion of air pollutants. This new definition is a natural extension of the usual 
derivative and satisfies practically all the properties of the integer calculus. And at this point, all other definitions of fractional derivatives fail, as they do not satisfy the product properties of two functions, quotient between two functions and chain rule. However, the discussion of a conformable derivative being a definition of a fractional derivative is still an open topic in the literature [5].

Thus, if the function $f$ is differentiable in $x>0, \alpha \in(0,1)$, the definition of a conformable derivative is given by:

$$
T_{\alpha}[f(x)]=x^{1-\alpha} \frac{d f(x)}{d x} .
$$

The LDM method, often called the Adomian decomposition method, allows for the reduction of the computational effort required to solve a differential equation and improve the accuracy of the results [11]. Thus, in this work, the equation to be solved is given by:

$$
U \frac{\partial c(x, z)}{\partial x}=K_{z}(x) \frac{\partial^{2} c(x, z)}{\partial z^{2}} .
$$

The traditional way for Eq. (2) to incorporate a fractional derivative can be obtained by the simple change given by,

$$
\frac{\partial}{\partial x} \rightarrow \frac{1}{\phi^{1-\alpha}} \frac{\partial}{\partial x^{\alpha}}
$$

resulting,

$$
\frac{U}{\phi^{1-\alpha}} \frac{\partial^{\alpha} c(x, z)}{\partial x^{\alpha}}=K_{z}(x) \frac{\partial^{2} c(x, z)}{\partial z^{2}}, \quad 0<\alpha \leq 1
$$

using fractional derivative property given by the Eq. (1), it is replaced in Eq. (4),

$$
\frac{U}{\phi^{1-\alpha}} x^{1-\alpha} \frac{\partial c(x, z)}{\partial x}=K_{z}(x) \frac{\partial^{2} c(x, z)}{\partial z^{2}}
$$

where $U$ is the mean longitudinal wind speed, $\phi^{1-\alpha}$ is a parameter to maintain dimensional consistency, $K_{z}$ is the vertical eddy diffusivity, and $\alpha$ is the parameter that represents the order of the derivative. In this work, the following eddy diffusivity is used:

$$
K_{z}(x)=\left(\frac{\sigma_{w}}{U}\right)^{2} U x=\omega x
$$

and $\omega$ is a constant. So,

$$
\frac{U}{\phi^{1-\alpha}} \frac{\partial c(x, z)}{\partial x}=\omega x^{\alpha} \frac{\partial^{2} c(x, z)}{\partial z^{2}} .
$$

A change of variable is made, such that,

$$
x^{*}=\int_{0}^{x} x^{\alpha} d x=\frac{x^{\alpha+1}}{\alpha+1}
$$


obtaining, the equation to be solved in this work,

$$
\frac{U}{\phi^{1-\alpha}} \frac{\partial c\left(x^{*}, z\right)}{\partial x^{*}}=\omega \frac{\partial^{2} c\left(x^{*}, z\right)}{\partial z^{2}}
$$

with $x>0$ and $0<z<h$. The Eq. (9) is the case where the coefficients are constant. Thus, the usual zero-flow condition of contaminants on the surface and at the top of the vertical domain is used,

$$
\omega \frac{\partial c}{\partial z}=0 \quad \text { at } \quad z=0, h
$$

where $h$ is the height of the planetary boundary layer (PBL), and also, there is an emission rate $Q$ at height of the source, $H_{s}$, given by,

$$
c(0, z)=\frac{Q}{U} \delta\left(z-H_{s}\right) \quad \text { at } \quad x=0 .
$$

The LDM method requires an approximation of the Dirac delta function $\delta($.$) ,$ given by,

$$
\delta\left(z-H_{s}\right)=\frac{1}{h}\left[1+2 \sum_{n=1}^{\infty}\left[\cos \left(\lambda_{n} z\right) \cos \left(\lambda_{n} H_{s}\right)\right]\right]
$$

and the eigenvalues are given by $\lambda_{n}=\frac{n \pi}{h}(n=1,2,3, \ldots)$.

Thus, the source condition expressed by Eq. (11) can be rewritten as,

$$
c(0, z)=\frac{Q}{U h}\left[1+2 \sum_{n=1}^{\infty}\left[\cos \left(\lambda_{n} z\right) \cos \left(\lambda_{n} H_{s}\right)\right]\right]
$$

Therefore, after defining the boundary and source conditions, the Laplace transform $\left(£_{\alpha}\right)$ in Eq. (9) is applied, such that,

$$
[s c(s, z)-c(0, z)]=\frac{\omega \phi^{1-\alpha}}{U} £_{\alpha}\left[\frac{\partial^{2} c\left(x^{*}, z\right)}{\partial z^{2}}\right]
$$

fixing the equation, is obtained,

$$
c(s, z)=\frac{c(0, z)}{s}+\frac{\omega \phi^{1-\alpha}}{U s} £_{\alpha}\left[\frac{\partial^{2} c\left(x^{*}, z\right)}{\partial z^{2}}\right] .
$$

Applying the Laplace inverse $\left(\mathfrak{£}_{\alpha}^{-1}\right)$, at Eq. (15),

$$
\mathfrak{f}_{\alpha}^{-1}[c(s, z)]=\mathfrak{£}_{\alpha}^{-1}\left[\frac{c(0, z)}{s}\right]+\mathfrak{f}_{\alpha}^{-1}\left[\left(\frac{\omega \phi^{1-\alpha}}{U s}\right) £_{\alpha}\left[\frac{\partial^{2} c\left(x^{*}, z\right)}{\partial z^{2}}\right]\right]
$$

then

$$
c\left(x^{*}, z\right)=c_{o}+£_{\alpha}^{-1}\left[\left(\frac{\omega \phi^{1-\alpha}}{U s}\right) £_{\alpha}\left[\frac{\partial^{2} c\left(x^{*}, z\right)}{\partial z^{2}}\right]\right]
$$


thus $c_{o}$ is given by,

$$
c_{o}=\frac{Q}{U h}+\frac{2 Q}{U h} \sum_{n=1}^{\infty} \cos \left(\lambda_{n} z\right) \cos \left(\lambda_{n} H_{s}\right)
$$

and, the remaining terms of the series, are obtained by the recurrence formula,

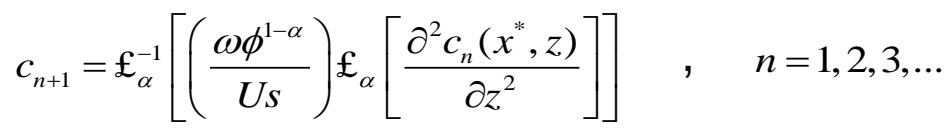

Proceeding, it is calculated $c_{1}$,

$$
\begin{gathered}
c_{1}=£_{\alpha}^{-1}\left[\left(\frac{\omega \phi^{1-\alpha}}{U s^{2}}\right) £_{\alpha}\left(\frac{\partial^{2} c_{o}\left(x^{*}, z\right)}{\partial z^{2}}\right)\right] \\
c_{1}=-\left[\left(\frac{\omega \phi^{1-\alpha}}{U}\right) \frac{x^{*}}{1 !}\left(\frac{2 Q}{U h} \sum_{n=1}^{\infty} \lambda_{n}^{2} \cos \left(\lambda_{n} z\right) \cos \left(\lambda_{n} H_{s}\right)\right)\right]
\end{gathered}
$$

similarly, $c_{2}$ and $c_{3}$,

$$
\begin{gathered}
c_{2}=\left[\left(\frac{\omega \phi^{1-\alpha}}{U}\right)^{2} \frac{x^{* 2}}{2 !}\left(\frac{2 Q}{U h} \sum_{n=1}^{\infty} \lambda_{n}^{4} \cos \left(\lambda_{n} z\right) \cos \left(\lambda_{n} H_{s}\right)\right)\right] \\
c_{3}=-\left[\left(\frac{\omega \phi^{1-\alpha}}{U}\right)^{3} \frac{x^{* 3}}{3 !}\left(\frac{2 Q}{U h} \sum_{n=1}^{\infty} \lambda_{n}^{6} \cos \left(\lambda_{n} z\right) \cos \left(\lambda_{n} H_{s}\right)\right)\right]
\end{gathered}
$$

Thus, grouping the first terms, is obtained,

$$
c\left(x^{*}, z\right)=\frac{Q}{U h}+\frac{2 Q}{U h} \sum_{n=1}^{\infty} \lambda_{n} \cos \left(\lambda_{n} z\right) \cos \left(\lambda_{n} H_{s}\right)\left[1-\frac{1}{1 !}\left(\frac{\omega \phi^{1-\alpha}}{U} x^{*}\right)^{1} \lambda_{n}^{2}+\frac{1}{2 !}\left(\frac{\omega \phi^{1-\alpha}}{U} x^{*}\right)^{2} \lambda_{n}^{4}-\frac{1}{3 !}\left(\frac{\omega \phi^{1-\alpha}}{U} x^{*}\right)^{3} \lambda_{n}^{6}+\ldots\right]
$$

Therefore, returning for the variable $x$, is obtained the final solution given by,

$$
c(x, z)=\frac{Q}{U h}+\frac{2 Q}{U h} \sum_{n=1}^{\infty} \cos \left(\lambda_{n} z\right) \cos \left(\lambda_{n} H_{s}\right) \exp \left(-\left(\frac{\sigma_{w}}{U}\right)^{2} \frac{\phi^{1-\alpha} x^{\alpha+1}}{\alpha+1} \lambda_{n}^{2}\right)
$$

The solution given by Eq. (25) is the first in atmospheric problems using the definition of a conformable derivative. It is observed that the solution has an exponential function, as expected for integer-order problems.

It is worth mentioning that there is a current debate about the admission of the derivative conformable as a fractional derivative. Besides, there is another debate about the fact that, when using a fractional derivative, the problem in question becomes dimensionally inconsistent, which is a current gap, requiring the insertion of a correction parameter and dimensional consistency, which is here given by $\phi^{1-\alpha}$. In this work, to evaluate the behavior of this parameter, which has a dimension of length $(L)$, the following hypotheses are adopted, $\phi=1$ e $\phi=h$ (PBL height) with a variation of $\alpha$ in the interval $0<\alpha \leq 1$. 


\section{RESULTS AND DISCUSSION}

The data obtained by the model were compared with the data from the Copenhagen experiments. The dispersion experiments in Copenhagen [12,13], consisted of releasing the tracer $S F_{6}$ (sulfur hexafluoride) at $115 \mathrm{~m}$ height, considering distances between 2 and $6 \mathrm{~km}$ from the source. In this experiment, the laterally integrated concentration was normalized by the emission rate $(c(x, 0) / Q)$.

To evaluate the results obtained in this approach with a conformable derivative, Figure 1 shows the convergence of the solution, considering $\phi=1 \mathrm{~m}$ with the fractional parameter given by the values $\alpha=1.0,0.9,0.8$, with source distance of $100 \mathrm{~m}$.

Figure 1 - Convergence curves of the solution for the distance $100 \mathrm{~m}$, using data from experiment 1 of Copenhagen.

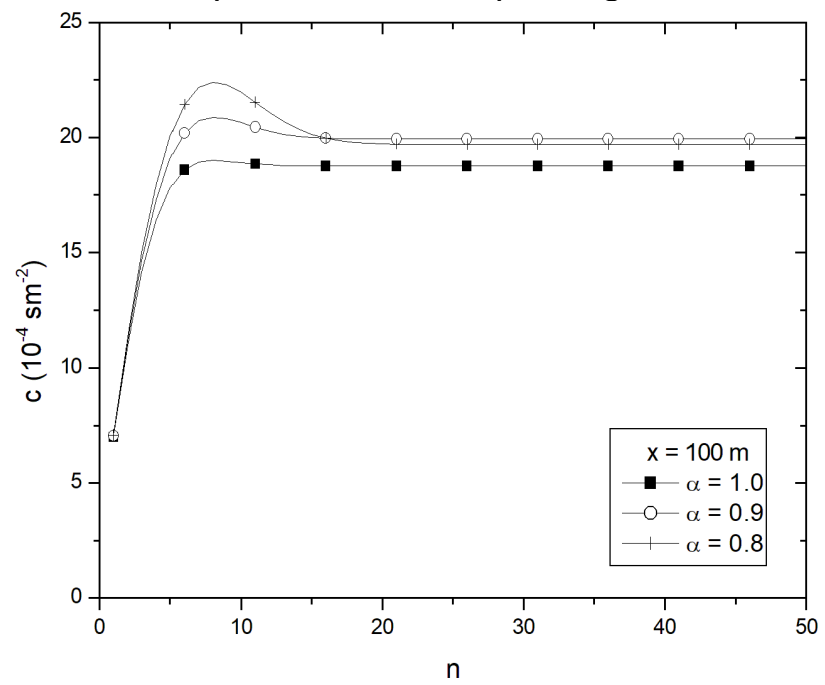

It can be seen in Figure 1 that the solution is given by Eq. (25) shows a fast convergence.

Table 1 presents the statistical indices for assessing the model's performance. For an optimal assessment, the NMSE, FS, and FB indices must be zero, and COR and FAT2 must be one.

Table 1 - Statistical evaluation of the model performance: NMSE (normalized mean square error), COR (correlation coefficient), FAT2 (factor of two), FB (fractional bias), and FS

(standard deviation).

(a)

\begin{tabular}{|c|c|c|c|c|c|}
\hline \multicolumn{7}{|c|}{$\phi=1$} \\
\hline Model & NMSE & COR & FA2 & FB & FS \\
\hline$\alpha=1,00$ & 0,52 & 0,75 & 0,52 & 0,53 & 0,19 \\
\hline$\alpha=0,90$ & 0,45 & 0,78 & 0,52 & 0,50 & 0,21 \\
\hline$\alpha=0,80$ & 0,33 & 0,82 & 0,70 & 0,42 & 0,26 \\
\hline$\alpha=0,70$ & 0,18 & 0,87 & 0,96 & 0,28 & 0,32 \\
\hline$\alpha=0,60$ & 0,08 & 0,88 & 1,00 & 0,08 & 0,34 \\
\hline$\alpha=0,50$ & 0.11 & 0.83 & 0.87 & -0.16 & 0,30 \\
\hline
\end{tabular}

(b)

\begin{tabular}{|c|c|c|c|c|c|}
\hline \multicolumn{7}{|c|}{$\phi=h$} \\
\hline Model & NMSE & COR & FA2 & FB & FS \\
\hline$\alpha=1,00$ & 0,52 & 0,75 & 0,52 & 0,53 & 0,19 \\
\hline$\alpha=0,90$ & 0,53 & 0,74 & 0,52 & 0,53 & 0,19 \\
\hline$\alpha=0,80$ & 0,53 & 0,74 & 0,52 & 0,53 & 0,19 \\
\hline$\alpha=0,70$ & 0,53 & 0,74 & 0,52 & 0,53 & 0,18 \\
\hline$\alpha=0,60$ & 0,54 & 0,74 & 0,52 & 0,54 & 0,18 \\
\hline$\alpha=0,50$ & 0,54 & 0,74 & 0,52 & 0,54 & 0,18 \\
\hline
\end{tabular}


It is observed in Table 1 (a) that the results with parameter $\phi$ equal to unit present the best results, in particular for $\alpha=0,6$, with the lowest NMSE $(0,08)$ and highest COR $(0,88)$ and FAT2 $(1,00)$. However, the results for $\phi$ equal to the height of the PBL showed unsatisfactory results.

Figure 2 shows the scatter plot of simulated concentrations at ground level.

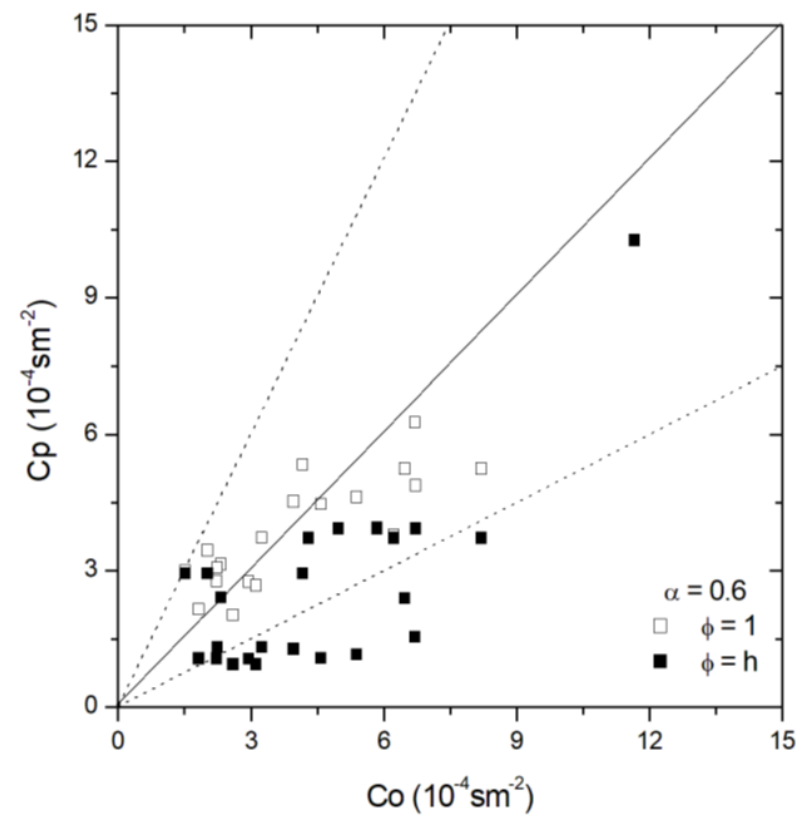

Figure 2 - Scattering of pollutant concentrations at ground level.

In general, analyzing Figure 2 and Table 1 , it is observed that the best result is for $\alpha=0,60$ and $\phi=1 \mathrm{~m}$ ( $\mathrm{Cp}$ is the concentration predicted by the model and $\mathrm{Co}$ is the concentration observed experimentally). This is an interesting result since the problem solved is dimensionally consistent, but it still needs a better analysis to justify this length scale. Besides, the fact that the conformable derivative transforms a fractional equation into an integer one, causes loss of memory effect in the solution of the advection-diffusion equation.

\section{CONCLUSION}

This work proposed an alternative method to obtain the solution of the fractional advection-diffusion equation. For this purpose, the Laplace decomposition method and the conformable derivative were used to simulate the dispersion of pollutants in the planetary boundary layer.

The results obtained in the simulations showed that the conformable derivative allows a quick and easy solution for the two-dimensional advection-diffusion equation. However, the solution obtained is an exponential function, characteristic of an integer order equation, generating a loss of memory effect that is a characteristic of fractional derivatives, whose solutions are usually related to the Mittag-Leffler function. Not least, a better analysis of the choice of the length scale in the dimensional adjustment must be considered. Therefore, more studies are needed in this direction, and this work 
presents the state of the art in analytical solutions of equations with fractional derivatives.

\section{Acknowledgments}

We thank FAPESB (BOL 0194/2019) for the financial support and SENAI-CIMATEC logistical support in the development of this work.

\section{REFERENCES}

${ }^{1}$ ROSS, B. A brief history, an exposition of the fundamental theory of fractional calculus. Fract. Cal. Appl., 57, 1-36, 1975.

BARBOSA, EF. A regra de L' Hôpital: análise histórica da regra de L' Hôpital - a importância da histórica da matemática na disciplina de cálculo / Everaldo Fernandes Barbosa -- Campinas, [S.P.: s.n.], 2008.

${ }^{3}$ OLIVEIRA, HS. Introdução ao cálculo de ordem arbitrária. UNICAMP-IMECC, 122 p. http://www.repositorio.unicamp.br/handle/REPOSIP/307000, Campinas, SP. 2010.

${ }^{4}$ ORTIGUEIRA, MD. MACHADO, JAT. What is a fractional derivative? J. Comp. Phys., 293, 4-13, 2015.

5TEODORO, GS. Derivadas fracionárias: tipos e critérios de validade. UnicampIMECC. Tese (doutorado)/Graziane Sales Teodoro. - Campinas, SP: [s.n.], 2019

${ }^{6} \mathrm{KHALIL}, \mathrm{R}$. et al. A new definition of fractional derivative. Journal of Computational and Applied Mathematics, v. 264, p. 65-70, 2014.

${ }^{7}$ PALMEIRA, AS. XAVIER, PHF. MOREIRA, DM. Simulation of atmospheric pollutant dispersion considering a bi-flux process and fractional derivatives. Atmospheric Pollution Research, v. 11, n. 1, p. 57-66, 2020.

${ }^{8}$ MOREIRA, DM. et al. Semi-analytical model for pollution dispersion in the planetary boundary layer. Atmospheric Environment, Elsevier, v. 39, n. 14, p. 2673-2681, 2005.

${ }^{9}$ MOREIRA, DM. et al. A contribution to solve the atmospheric diffusion equation with eddy diffusivity depending on source distance. Atmospheric Environment, Elsevier, v. 83, p. 254-259, 2014.

10TIRABASSI, T. et al. A two-dimensional solution of the advection-diffusion equation with dry deposition to the ground. Journal of Applied Meteorology and Climatology, v. 47 , n. 8 , p. $2096-2104,2008$

${ }^{11}$ MOREIRA, DM. XAVIER, PHF. PALMEIRA, AS. New approach to solving the atmospheric pollutant dispersion equation using fractional derivatives, International Journal of Heat and Mass Transfer, v, 144, p, 118667, Salvador, 2019

${ }^{12}$ GRYNING, SE. LYCK, E. Atmospheric dispersion from elevated sources in an urban area: comparison between tracer experiments and model calculations. J Clim Appl Meteorol 23(4):651-660, 1984

${ }^{13}$ GRYNING, SE. HOLTSLAG, AMM. IRWIN, J. SIVERTSEN, B. Applied dispersion modeling based on meteorological scaling parameters. Atmos Environ 21(1):79-89, 1987 